\title{
Assessment of body balance of patients treated with the Ilizarov method for tibial nonunion
}

\author{
ANDŻELIKA PAJCHERT-KOZŁOWSKA ${ }^{1}$, ŁUKASZ PAWIK ${ }^{2}$, ŁUKASZ SZELERSKI $^{3}$, SŁAWOMIR ŻAREK ${ }^{3}$, \\ RAdosŁaw GÓRSKI ${ }^{3}$, MALWINA PAWIK ${ }^{4}$, FELICJA FINK-LWOW ${ }^{4}$, PIOTR MORASIEWICZ ${ }^{1} *$ \\ ${ }^{1}$ Wroclaw Medical University, Department and Clinic of Orthopaedic and Traumatologic Surgery, Wrocław, Poland. \\ ${ }^{2}$ Department of Physiotherapy in Motor Disorders and Dysfunctions, \\ University School of Physical Education in Wrocław, Wrocław, Poland. \\ ${ }^{3}$ Medical University of Warsaw, Department of Orthopedics and Musculoskeletal Traumatology, Warsaw, Poland. \\ ${ }^{4}$ Health Promotion, Faculty of Physiotherapy, University School of Physical Education in Wrocław, Wrocław, Poland.
}

\begin{abstract}
Purpose: The biomechanics of the musculoskeletal system in patients after tibial nonunion treatment using the Ilizarov method have not yet been fully explored. From the orthopaedic and patient point of view, after the treatment, an assessment should be carried out of the biomechanics of the musculoskeletal system. The aim of this study was to assess the body balance of patients treated with the Ilizarov method for tibial nonunion. Methods: The research group included 24 individuals with a mean age of 55 years, who were treated for aseptic tibial nonunion with the Ilizarov method. The control group was matched to the study group in terms of gender and age, and consisted of 32 subjects with a mean age of 50.5 years and no significant medical history. This study evaluated the balance of patients with the use of pedobarography. Results: In the control group, a statistically significantly shorter path of centre of gravity was observed. There were no statistical differences between the study and control groups for the field area of the centre of gravity. There were no statistical differences between the study and control groups for the minor axis length or major axis length of the centre of gravity. There was a relationship between the centre of pressure path length and the age of the participants in both the control group and the study group. Conclusions: Treatment of patients with tibial nonunion with the Ilizarov fixator achieves similar balance to healthy volunteers. In the pedobarographic evaluation, patients treated for tibial nonunion using the Ilizarov method had similar statics of the musculoskeletal system to healthy volunteers.
\end{abstract}

Key words: body balance, pedobarography, nonunion, tibia, Ilizarov method

\section{Introduction}

Tibial nonunion is a significant social problem hindering the quality of life of patients [21], [28]. The tibia is the most common location of nonunion [21], [28]. The treatment of nonunion is complex and associated with numerous complications [1], [8], [9], [11], [14], [15], [19], [21], [28]. The Ilizarov method is an internationally recognised and preferred method for the treatment of nonunion [1], [2], [7]-[12], [14], [15], [18], [19]-[21], [28], [29]. Most patients treated with this method have good results and achieve bone union
[1], [2], [8]-[10], [12], [15], [20], [21], [28], [29]. However, several authors have reported unsatisfactory results of tibial nonunion treatment, where not all patients achieved bone union [7], [11], [14], [19].

When assessing the outcomes from the treatment of lower limb diseases, it is important to evaluate the limb function in addition to routine clinical and radiological assessment [3], [5], [6], [23]. From the orthopaedic and patient point of view, after the treatment, an assessment should be carried out of the biomechanics of the musculoskeletal system [5], [6], [17], [23]-[25]. Normal joint mobility, muscular strength, proprioception and the absence of pain are all important

\footnotetext{
* Corresponding author: Piotr Morasiewicz, Wroclaw Medical University, ul. Borowska 213, 50-556 Wrocław, Poland. Phone: (48)504549666, e-mail: morasp@poczta.onet.pl

Received: April 20th, 2020

Accepted for publication: July 6th, 2020
} 
factors for restoring the normal biomechanics of the locomotor system [4], [13], [16], [22], [23], [25]-[27]. The pedobarographic platform enables reproducible, comparable and objective examination of the statics and dynamics of the musculoskeletal system [13], [22], [23], [25], [27].

The biomechanics of the musculoskeletal system in patients after tibial nonunion treatment using the Ilizarov method have not yet been fully explored. Researchers have focused on the clinical and radiological outcomes of patients treated with this method [1], [2], [7]-[12], [14], [15], [19]-[21], [28], [29]; however, no studies have assessed the statics of the musculoskeletal system in these patients.

Previous studies have used pedobarographic platforms to evaluate the statics of the musculoskeletal system in patients after thigh and lower leg corticotomy using the Iilizarov method [22], [25] and in ankle arthrodoses stabilised with the Ilizarov fixator [23].

The aim of this study was to assess the body balance of patients treated with the Ilizarov method for tibial nonunion.

\section{Materials and methods}

The clinical research group included 24 individuals with a mean age of 55 years (range 26.5 to 82.5 years) who were treated for aseptic tibial nonunion with the Ilizarov method (Table 1). The control group was matched to the study group in terms of gender and age, and consisted of 32 subjects with a mean age of 50.5 years (range 34.0 to 77.7 years) and no significant medical history (Table 1).

The criteria for inclusion in the study group were: treatment for aseptic tibia nonunion using the Ilizarov method, minimum follow-up period of 2 years from the completion of treatment, consent to participate in the study, radiological and clinical treatment records, data from a pedobarographic examination, and no other diseases of the lower limbs. The study was approved by the bioethics committee. All patients were informed about the voluntary nature of participation in the study.

In the case of nonunion up to a maximum of onethird of the distal tibia, the Ilizarov fixator consisted of four rings fixed to the tibia and fibula with Kirschner wires. In the case of nonunion up to a maximum level of the metaphysis and epiphysis of the distal tibia, the Ilizarov stabiliser consisted of three rings fixed to the tibia and fibula with Kirschner wires and one half-ring fixed to the foot bone with three Kirchner "olive" wires. Treatment of tibia nonunion using the Ilizarov method was performed through stabilisation and compression of the nonunion, without bone transport treatment. The distal surface of the proximal tibial fragment and the proximal surface of the distal fragment were always drilled with Kirschner wire according to Beck.

Gait with two elbow crutches commenced on the first day following surgery. Clinical and radiological outpatient follow-up was carried out every 2-6 weeks. During treatment, the load on the operated limb was gradually increased up to the point where the use of crutches could be discontinued, allowing patients to walk with full load on the limb.

The Ilizarov fixtor was removed after observing sufficient bone union within the nonunion site confirmed radiologically and clinically. The radiological criterion was the presence of a minimum of three out of four cortical layers or the continuous presence of trabecular transition between the bone fragments, which were visible on X-ray images in the anteroposterior and lateral views. The clinical criteria included a lack of pain, no pathological movement and no deformations of the lower limb following the dynamisation of the fixator and a powerful movement attempt in the area of the nonunion. After removal of the Ilizarov fixator, patients were recommended to walk with two elbow crutches for 4 weeks, with partial relief of the operated limb. The load distribution was increased gradually, taking the progression of nonunion bone remodelling into account, as revealed in the X-ray image.

This study evaluated the balance of patients treated for aseptic tibial nonunion with the Ilizarov method, using pedobarography. A Zebris Medical GmbH (Fig. 1) pedobarographic platform was used in the study. The pedobarographic platform has an area of $1580 \times 600 \mathrm{~mm}$ and includes 11264 sensors, allowing for both static and dynamic tests to be carried out. After connecting the platform to a computer equipped with the appropriate software (FootPrint), the two- and three-dimensional distribution of ground reaction forces during gait and in static conditions were analysed. This platform also allows for the analysis of deviations of the centre of gravity of the body in both static and dynamic tests. The use of this platform enabled computer registration of kinetic gait parameters, which were statistically analysed [22], [23].

Balance testing was performed without shoes, first with eyes open and then with eyes closed. Before each test, the device was calibrated and the study participant received detailed instructions and information about the structure of the test. The respondent stood motionless 
on the platform in a neutral position with their feet hip-width apart. The 30-s tests were performed with both their eyes open and closed. Each study was performed three times and the average result was further analysed [22], [23].

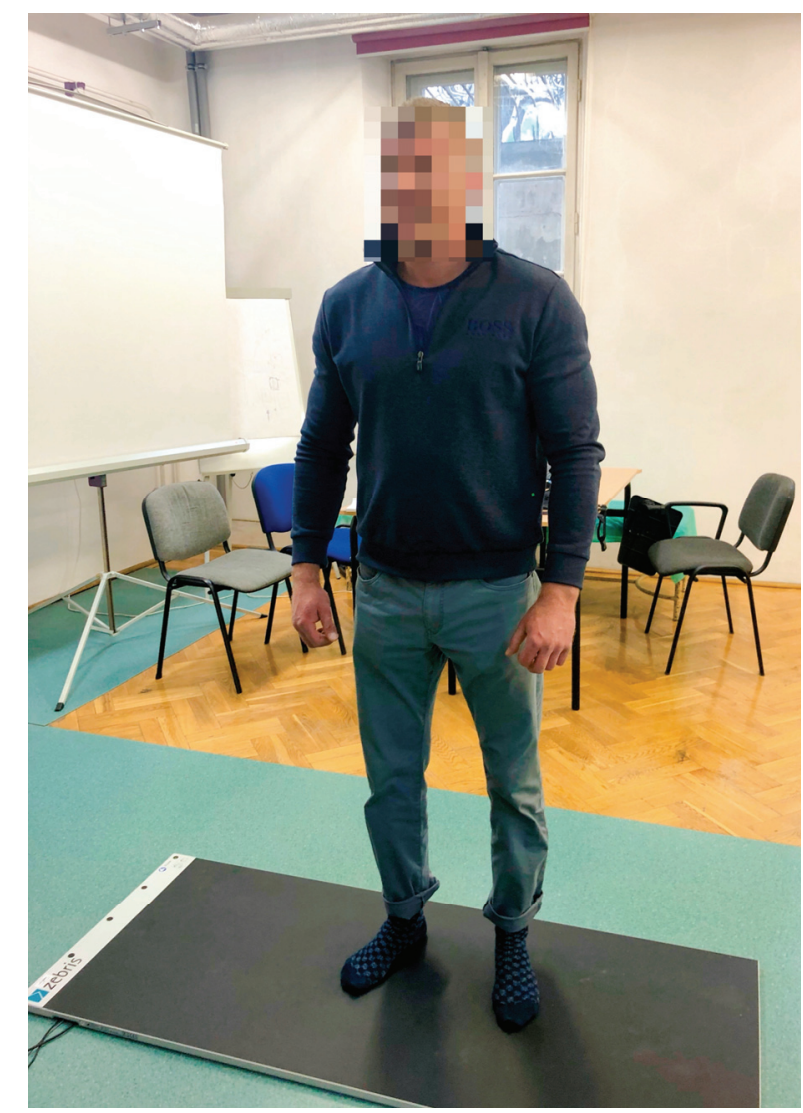

Fig. 1. Patient on a pedobarographic platform

Balance was measured as the distance travelled by the centre of gravity of the body during the measurement (length of the centre of gravity line created during the measurement, expressed in centimetres) and using the surface area that the centre of gravity of the body travelled during the measurement (area of displacement of the centre of gravity generated during the measurement, expressed in square centimetres), the minor axis length of the centre of gravity created during the measurement (expressed in millimetres) and the major axis length of the centre of gravity created during the measurement (expressed in millimetres) [22], [23]. All results were compared between the study group and the control group.

\section{Statistical analysis}

Data were analysed using the SigmaPlot v13 (Systat Software Inc., San Jose, CA, USA) statistics package. Continuous variables were firstly analysed using the Kolmogorov-Smirnov test with the Lilliefors correc- tion to confirm a normal distribution. All values were expressed as the median and the 5th and 95th percentiles. An unpaired Student's $t$-test was used to examine the differences between the two groups. For data that was not normally distributed, the significance of differences was analysed using the Mann-Whitney $U$-test. Linear regression analyses were performed to evaluate the associations between the balance parameters and the age and body mass index (BMI) of the participants. The level of statistical significance was set at $p<0.05$.

\section{Results}

The study and control groups did not differ in terms of age, body weight, height or BMI (Table 1).

Table 1. Characteristics of the participants

\begin{tabular}{|l|c|c|c|}
\hline & $\begin{array}{c}\text { Control group } \\
(n=32)\end{array}$ & $\begin{array}{c}\text { Patients after } \\
\text { surgery }(n=24)\end{array}$ & $P$ \\
\hline Age [years] & $50.5(34.0-77.7)$ & $55.0(26.5-82.5)$ & 0.758 \\
\hline Height $[\mathrm{cm}]$ & $170(150.5-191.2)$ & $172.5(158.3-187.7)$ & 0.297 \\
\hline Body mass $[\mathrm{kg}]$ & $79.5(56.0-99.8)$ & $79.5(48.0-105.2)$ & 0.261 \\
\hline BMI $\left[\mathrm{kg} / \mathrm{m}^{2}\right]$ & $27.2(21.6-36.4)$ & $27.8(20.5-36.4)$ & 0.098 \\
\hline
\end{tabular}
index.

Data are medians and 5 th-95th percentiles, BMI - body mass

Measurements of the centre of gravity path and field area for the study and control groups with eyes open and closed are presented in Table 2. In the control group, a statistically significantly shorter path of centre of gravity was observed (eyes open, $p=0.001$; eyes closed, $p<0.001$ ). There were no statistical differences between the study and control groups for the field area of the centre of gravity.

The values of minor axis length and major axis length of the centre of gravity for the study and control groups with eyes open and closed are presented in Table 3. There were no statistical differences between the study and control groups for the minor axis length or major axis length of the centre of gravity.

To determine whether the centre of pressure (COP) path length is associated with the age of the participants, a linear regression analysis was performed. As shown in Fig. 2, there was a relationship between the COP path length and the age of the participants in both the control group and the study group. The value of this balance parameter increased with the participants' age; this relationship was statistically significant for all groups examined independently, whether 
Table 2. Center of pressure path length and area of the center of presssure

\begin{tabular}{|l|c|c|c|}
\hline \multicolumn{1}{|c|}{ Balance parameter } & $\begin{array}{c}\text { Control group } \\
(n=32)\end{array}$ & $\begin{array}{c}\text { Patients after surgery } \\
(n=24)\end{array}$ & $P$ \\
\hline $\begin{array}{l}\text { 95\% confidence COP area }\left[\mathrm{cm}^{2}\right] \\
\text { open eyes }\end{array}$ & $1.81(0.50-4.87)$ & $3.21(0.48-12.15)$ & 0.130 \\
\hline $\begin{array}{l}\text { 95\% confidence COP area }\left[\mathrm{cm}^{2}\right] \\
\text { closed eyes }\end{array}$ & $1.81(0.52-5.90)$ & $2.13(0.48-10.15)$ & 0.842 \\
\hline $\begin{array}{l}\text { COP path length }[\mathrm{cm}] \\
\text { open eyes }\end{array}$ & $30.1(12.1-73.2)$ & $55.4(20.3-166.4)$ & $\mathbf{0 . 0 0 1}$ \\
\hline $\begin{array}{l}\text { COP path length }[\mathrm{cm}] \\
\text { closed eyes }\end{array}$ & $50.5(23.9-114.8)$ & $92.9(28.1-211.4)$ & $<\mathbf{0 . 0 0 1}$ \\
\hline
\end{tabular}

Data are medians and 5th-95th percentiles, bold typeface indicates statistically significant differencies, COP - center of pressure.

Table 3. Length of minor axis and Length of major axis

\begin{tabular}{|l|c|c|c|}
\hline \multicolumn{1}{|c|}{ Balance parameter } & $\begin{array}{c}\text { Control group } \\
(n=32)\end{array}$ & $\begin{array}{c}\text { Patients after surgery } \\
(n=24)\end{array}$ & $P$ \\
\hline $\begin{array}{l}\text { Length of minor axis [mm] } \\
\text { Open eyes }\end{array}$ & $9.5(3.9-19.8)$ & $14.5(4.6-32.8)$ & 0.150 \\
\hline $\begin{array}{l}\text { Length of minor axis [mm] } \\
\text { Closed eyes }\end{array}$ & $10.0(4.9-24.1)$ & $10.4(4.8-33.2)$ & 0.888 \\
\hline $\begin{array}{l}\text { Length of major axis [mm] } \\
\text { Open eyes }\end{array}$ & $22.7(10.9-36.2)$ & $25.8(7.4-37.1)$ & 0.691 \\
\hline $\begin{array}{l}\text { Length of major axis [mm] } \\
\text { Closed eyes }\end{array}$ & $23.9(12.4-41.5)$ & $27.2(10.6-41.5)$ & 0.703 \\
\hline
\end{tabular}

Data are medians and 5th-95th percentiles, bold typeface indicates statistically significant differencies.
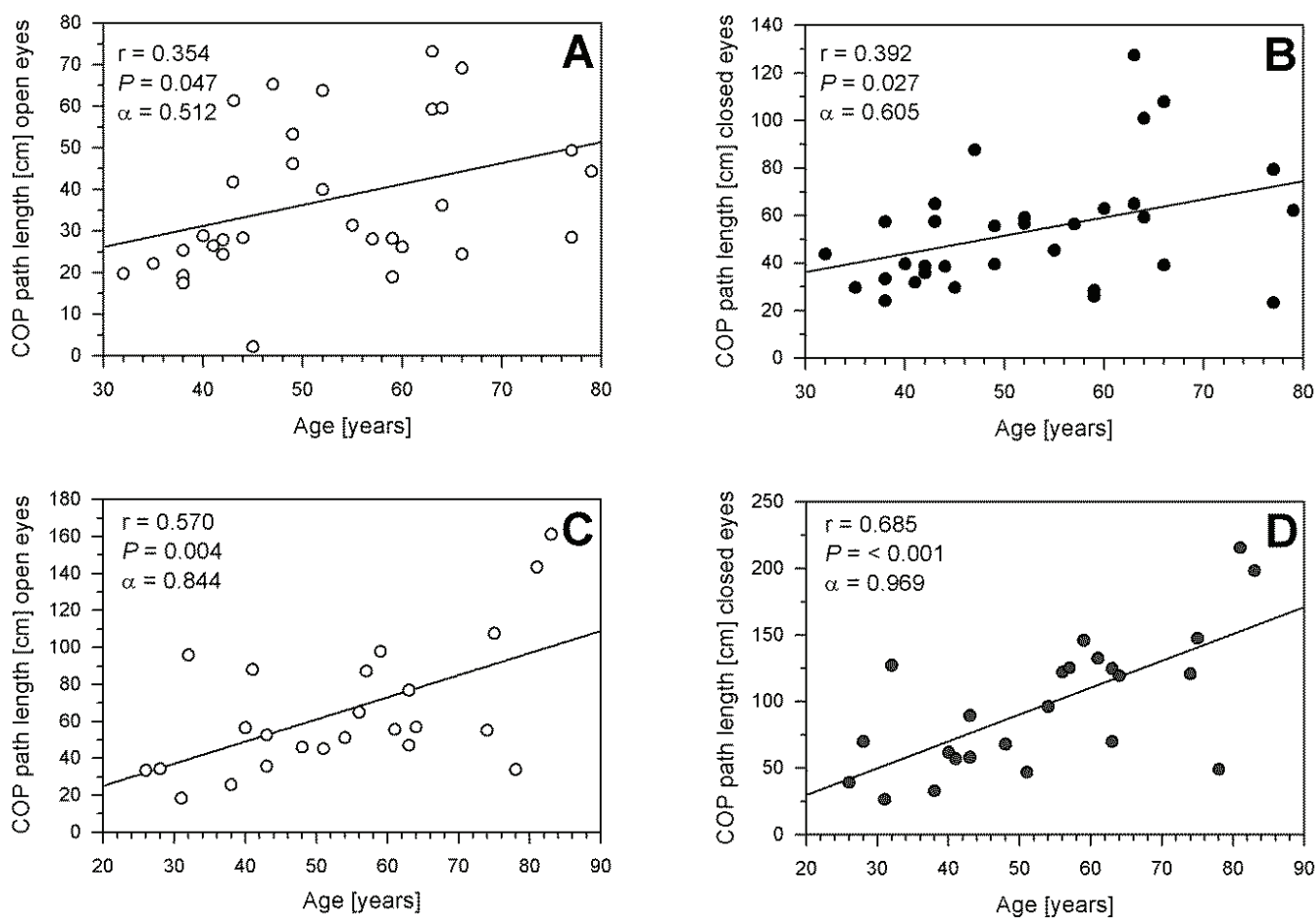

Fig. 2. Relationship between the centre of pressure (COP) path length and the age of participants in the control group (A and B) and in patients after surgery $(\mathrm{C}$ and $\mathrm{D})$. Open symbols represent tests performed with eyes open; filled symbols represent tests performed with eyes closed, $r$-correlation coefficient; $\alpha$ - power of the linear regression analysis 
the COP path length was measured with eyes open or closed. The $p$-values for all analyses were below 0.05 (Figs. 2A-D); however, the power of tests only exceeded the desired value of 0.800 in the study group (Figs. 2C, D). For the control group, $p$-values of 0.512 and 0.605 were obtained for tests performed with eyes open and closed, respectively (Figs. 2A, B).

The results of the linear regression analyses show that BMI had no effect on the COP path length in both the study and control groups.

\section{Discussion}

The treatment of tibial nonunion remains a challenge for orthopaedists [1], [8], [9], [11], [14], [15], [19], [21], [28]. The tibia is the most common location of the nonunion [21], [28], but the results of treatment are not always completely satisfactory [7], [11], [14], [19].

Authors of previous studies have focused on presenting various techniques for the treatment of tibial nonunion, often only evaluating clinical and radiological results [1], [2], [7]-[12], [14], [15], [19]-[21]. In previous studies, authors focused on forces in the Ilizarov fixatros [17], [24]. Until now, the biomechanics of the musculoskeletal system had not been studied in patients who had undergone tibial nonunion treatment using the Ilizarov method. Furthermore, no studies have evaluated the balance of these patients.

The elimination or reduction of pain and improvement or restoration of normal joint mobility, muscular strength and proprioception work together to enhance the biomechanical properties of the musculoskeletal system [4], [13], [16], [22], [23], [26], [27].

In previous studies, researchers have observed limitations in the joint mobility of some patients following tibial nonunion treatment, which may affect the biomechanics of the musculoskeletal system [18], [20], [29].

In a study by McHale on 10 patients with tibial nonunion who were treated by the Ilizarov method, six patients were found to have significantly reduced function of their lower limbs due to decreased muscle strength and limited ankle or knee mobility [18].

Rongies and colleagues evaluated 21 patients with coxarthrosis using a pedobarographic platform and observed a correlation between pain relief and enhanced balance [27].

Morasiewicz et al. [22], [23], [25] observed an improvement in the statics of the musculoskeletal system in patients after thigh and lower leg corticotomy using the Ilizarov method and after ankle arthrodesis using the Ilizarov method. According to the pedobarographic assessment, balance parameters improved after the treatment, but they did not reach the same level as healthy subjects from the control group [22], [23].

The results of the present study are similar to those of earlier pedobarographic studies [22], [23], [25]. Three out of four balance parameters evaluated in patients after nonunion treatment did not differ statistically from the results of the control group of healthy volunteers. This may indicate a return to almost normal static properties of lower limb biomechanics in patients after Ilizarov tibial nonunion treatment.

According to the results of pedobarographic assessment in the current study, patients who had undergone tibial nonunion treatment using the Ilizarov method achieved balance parameters similar to those of healthy individuals. Thus, it can be concluded that in the treatment of tibial nonunion, the Ilizarov method allows for pain relief and the restoration of normal muscle strength and joint mobility.

The results of linear regression analysis lead us to conclude that the COP path length is dependent on the age of subjects, as observed in both the study and control groups. In the case of the study group, such a conclusion was expected, as $p$-values were lower than 0.05 and the power of analysis was increased to 0.800 . This conclusion also seems to be valid for the control group $(p<0.05)$, but this result should be interpreted with caution as the power of analysis was lower than the desired 0.800 , which is probably due to the high variability of data.

The results of the linear regression analyses for both the study and control groups suggest that the subject's BMI had no effect on the COP path length. However, this result should be interpreted with caution as the power of analysis was much lower than the desired 0.800 , which is probably due to the small group size and the high variability of data. Thus, it seems possible that a second-order error could have occurred, and, therefore, a firm conclusion about the lack of dependence between COP length and BMI cannot be made.

One of the limitations of our study is the lack of balance assessment prior to treatment. This is due to the small number of patients with tibial nonunion who were assessed using the pedobarographic platform before and after surgery. Before treatment, most patients had severe pain and significant walking problems due to the tibial nonunion, which made it difficult to examine them using the pedobarographic platform. In the future, we plan to study the statics of the musculoskeletal system before and after tibial nonunion treatment. A strength of our work is that the surgery was performed by three surgeons, all using the same technique with the same postoperative treatment protocol. 


\section{Conclusions}

In conclusion, it can be stated that treatment of patients with tibial nonunion by stabilisation using the Ilizarov fixator achieves similar balance to healthy volunteers. Furthermore, in the pedobarographic evaluation, patients treated for tibial nonunion using the Ilizarov method had similar statics of the musculoskeletal system to healthy volunteers.

\section{Conflict of interests}

There was no conflict of interest for all authors.

\section{References}

[1] Abuomira I.E., Sala F., Elbatrawy Y., Lovisetti G., Alati S., CAPITANi D., Distraction osteogenesis for tibial nonunion with bone loss using combined Ilizarov and Taylor spatial frames versus a conventional circular frame, Strategies Trauma Limb Reconstr., 2016, 11 (3), 153-159.

[2] BARUAH R.K., Ilizarov methodology for infected non union of the Tibia: Classic circular transfixion wire assembly vs. hybrid assembly, Indian J. Orthop. [serial online], 2007, 41, 198-203. Available from: http://www.ijoonline.com/text.asp?2007/41/ 3/198/33682 [accessed: January 14, 2019],

[3] Bednarz P., Beal's T., Manila A., Subtalar distraction bone blok fusion: an assessment of outcome, Foot Ankle Int., 1997, 18, 785-791.

[4] Bhave A., Paley D., Herzenberg J., Improvement in Gait Parameters After Lengthening for the Treatment of Limb-Length Discrepancy, J. Bone Joint Surg. Am., 1999, 81, 529-534.

[5] Chahal J., Stephen D.J., Bulmer B., Daniels T., Kreder H.J., Factors associated with outcome after subtalar arthrodesis, J. Orthop. Trauma, 2006, 20 (8), 555-561.

[6] Dalat F., Trouillet F., Fessy M.H., Bourdin M., Besse J.L., Comparison of quality of life following total ankle arthroplasty and ankle arthrodesis: Retrospective study of 54 cases, Orthop. Traumatol. Surg. Res., 2014, 100 (7), 761-766.

[7] DRÓżDż M., RAK S., BARTOSZ P., BIAŁECKI J., MARCZYŃSKi W., Results of the Treatment of Infected Nonunions of the Lower Limbs Using the Ilizarov Method, Ortop. Traumatol. Rehabil., 2017, 12, 19 (2), 111-125.

[8] ERAlp İ.L., KocAOĞLu M., Dikmen G., AZAm M.E., Balci H.İ., BILEN F.E., Treatment of infected nonunion of the juxta-articular region of the distal tibia, Acta Orthop. Traumatol. Turc., 2016, 50 (2), 139-146, DOI: 10.3944/AOTT.2015.15.0147.

[9] Hosny G., Shawky M.S., The treatment of infected nonunion of the tibia by compression-distraction techniques using the Ilizarov external fixator, Int. Orthop., 1998, 22 (5), 298-302.

[10] Hosny G.A., Ahmed A.A., Hussein M.A., Clinical outcomes with the corticotomy-first technique associated with the Ilizarov method for the management of the septic long bones non-union, Int. Orthop., 2018, 42(12), 2933-2939, DOI: 10.1007/s00264-018-3924-9. Epub. 2018, Apr. 7.
[11] Khan M.S., Rashid H., Umer M., QAdiR I., HafeEz K., IQBAL A., Salvage of infected non-union of the tibia with an Ilizarov ring fixator, J. Orthop. Surg. (Hong Kong), 2015, 23 (1), 52-55.

[12] Laursen M.B., Lass P., Christensen K.S., Ilizarov treatment of tibial nonunions results in 16 cases, Acta Orthop. Belg., 2000, 66 (3), 279-285.

[13] LORKOWSKI J., TRYBUS M., HŁADKI W., BRONGEL L., Underfoot pressure distribution of a patient with unilateral ankylosis of talonavicular joint during rheumatoid arthritis - case report, Przegl. Lek., 2008, 65, 54-56.

[14] Madhusudhan T.R., Ramesh B., Manjunath K., SHAh H.M., SUNDARESH D.C., KRISHNAPPA N., Outcomes of Ilizarov ring fixation in recalcitrant infected tibial non-unions - a prospective study, J. Trauma Manag. Outcomes, 2008, 23, 2 (1), 6, DOI: 10.1186/1752-2897-2-6.

[15] Magadum M.P., Basavaraj Yadav C.M., PhaneEsha M.S., RAMESH L.J., Acute compression and lengthening by the Ilizarov technique for infected nonunion of the tibia with large bone defects, J. Orthop. Surg. (Hong Kong), 2006, 14 (3), 273-279.

[16] Majewski M., Bischoff-Ferrari H., GruneberG C., Dick W., Allum J.H., Improvements in balance after total hip replacement, J. Bone Joint Surg. Br., 2005, 87, 1337-1343

[17] Martyniuk B., Morasiewicz P., WudarczyK S., Dragan S.F., FILIPIAK J., The impact of configuration of the Ilizarov fixator on its stiffness and the degree of loading of distraction rods, Clin. Biomech. (Bristol, Avon), 2019, 63, 79-84, DOI: 10.1016/j.clinbiomech.2019.02.020. Epub. 2019, Feb. 27.

[18] McHale K.A., Ross A.E., Treatment of infected tibial nonunions with debridement, antibiotic beads, and the Ilizarov method, Mil. Med., 2004, 169 (9), 728-734.

[19] McNally M., Ferguson J., Kugan R., Stubbs D., Ilizarov Treatment Protocols in the Management of Infected Nonunion of the Tibia, J. Orthop. Trauma, 2017, 31 Suppl 5, S47-S54.

[20] Megas P., Saridis A., Kouzelis A., Kallivokas A., Mylonas S., TyllianaKis M., The treatment of infected nonunion of the tibia following intramedullary nailing by the Ilizarov method, Injury, 2010, 41 (3), 294-299, DOI: 10.1016/ j.injury.2009.09.013.

[21] Meleppuram J.J., IBrahim S., Experience in fixation of infected non-union tibia by Ilizarov technique - a retrospective study of 42 cases, Rev. Bras. Ortop., 2016, 30, 52 (6), 670-675, DOI: 10.1016/j.rboe.2016.11.008.

[22] Morasiewicz P., Dragan S., Dragan S.Ł., Wrzosek Z., PAWIK Ł., Pedobarographic analysis of body weight distribution on the lower limbs and balance after Ilizarov corticotomies, Clin. Biomech., 2016, 31, 2-6.

[23] Morasiewicz P., Konieczny G., DejneK M., Urbański W., Dragan S.Ł., Kulej M., Dragan S.F., PaWiK Ł., Assessment of the distribution of load on the lower limbs and balance before and after ankle arthrodesis with the Ilizarov method, Sci. Rep., 2018, 24, 8(1), 15693, DOI: 10.1038/ s41598-018-34016-3.

[24] Morasiewicz P., FilipiaK J., Konietzko M., Dragan S., The impact of the type of derotation mechanism on the stiffness of the Ilizarov fixator, Acta Bioeng. Biomech., 2012, Vol. 14, No. 1, 67-73.

[25] Morasiewicz P., Dragan S., Pedobarographic evaluation of body weight distribution on the lower limbs and balance after derotation corticotomies using the Ilizarov method, Acta Bioeng. Biomech., 2013, Vol. 15, No. 2, 91-96.

[26] Radler C., Kranzl A., Manner H.M., Höglinger M., GANGER R., GRILL F., Torsional profile versus gait analysis: 
consistency between the anatomic torsion and the resulting gait pattern in patients with rotational malignment of the lower extremity, Gait Posture, 2010, 32, 405-410.

[27] Rongies W., BAK A., LAZAR A., A trial of the use of pedobarography in the assessment of the effectiveness of rehabilitation in patients with coxarthrosis, Ortop. Traumatol. Rehabil., 2009, 11, 242-252.
[28] WANi N.B., SYED B., Ilizarov ring fixator in the management of infected non-unions of tibia, SICOT J., 2015, 29, 1, 22, DOI: $10.1051 / \operatorname{sicotj} / 2015022$.

[29] Xu J., Jia Y.C., Kang Q.L., Chai Y.M., Management of hypertrophic nonunion with failure of internal fixation by distraction osteogenesis, Injury, 2015, 46 (10), 2030-2035, DOI: 10.1016/j.injury.2015.06.020. Epub 2015 Jun 17. 